\title{
Painful HIV-associated sensory neuropathy
}

\author{
Peter Kamerman
}

$16^{\text {th }}$ World Congress on Pain, Yokohama, Japan, 2016 


\section{Major neurological complications of HIV infection}

\section{Central nervous system}

HIV-associated neurocognitive disorders (HAND)

Myelopathy

\section{Peripheral nervous system}

HIV-associated sensory neuropathy (HIV-SN)

Inflammatory demyelinating polyneuropathies

Polyradiculopathy

Mononeuritis multiplex 


\section{Global prevalence of HIV-SN (adults): $30-60 \%$}

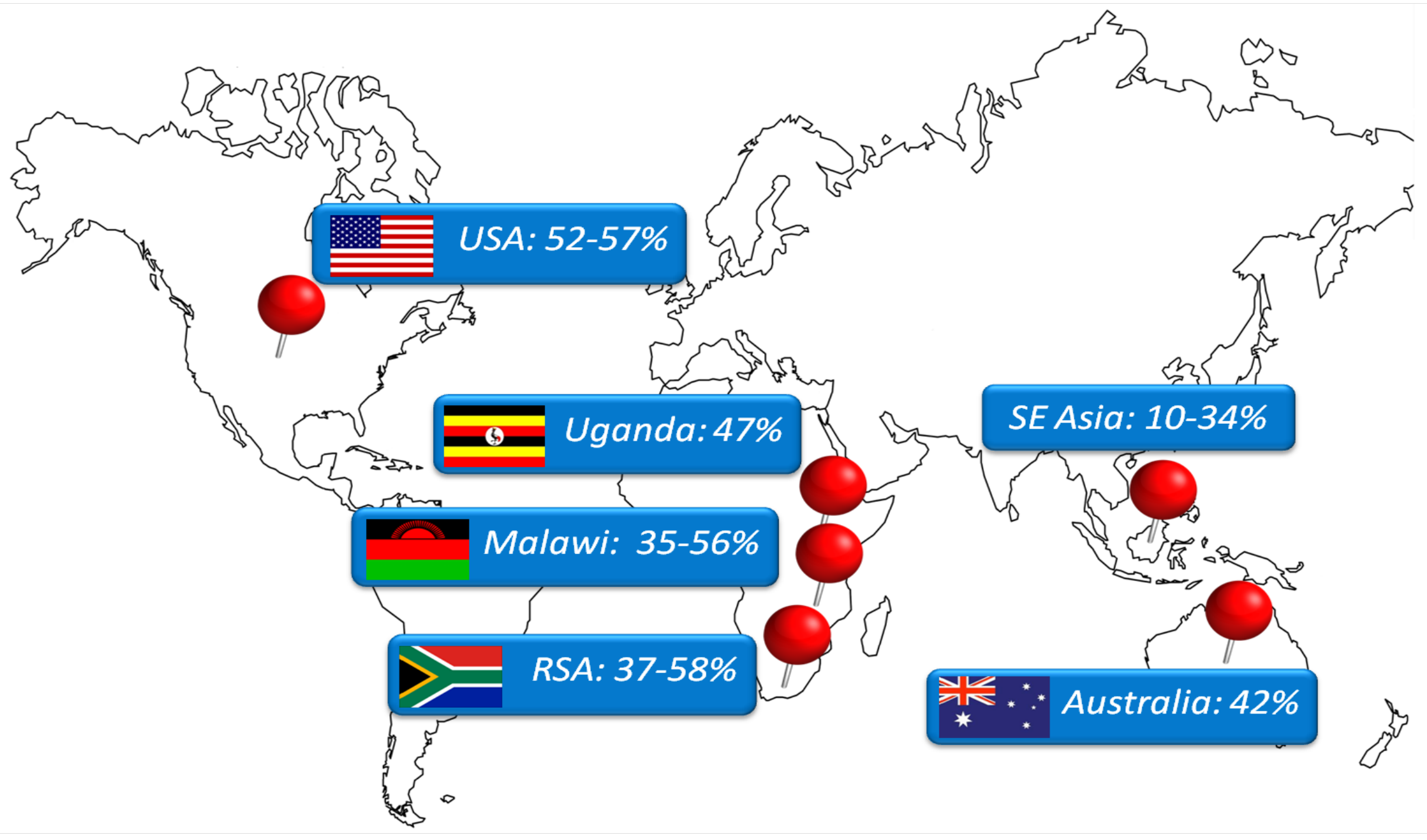




\section{Global prevalence of HIV-SN (children): $13-38 \%$}

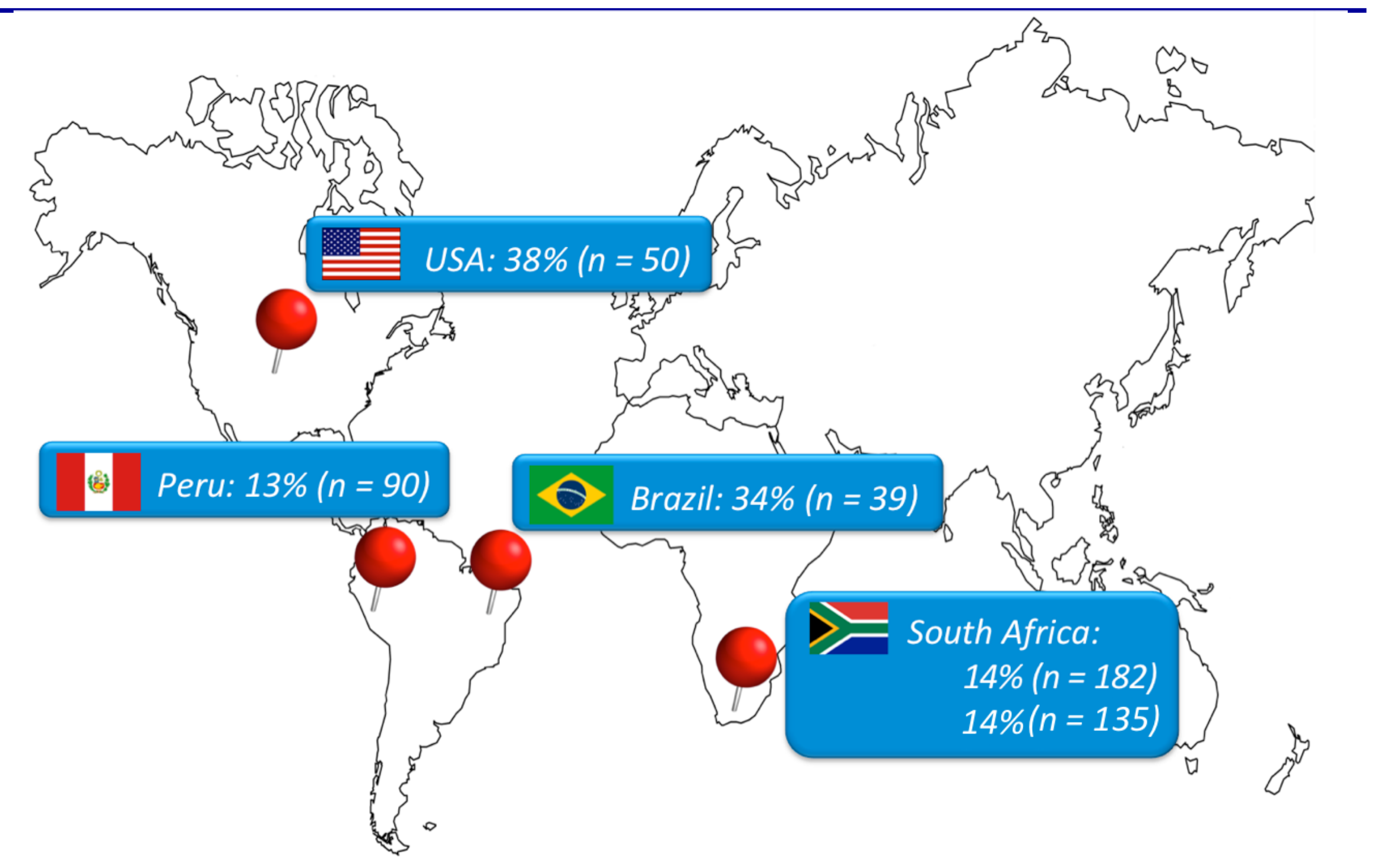

Araujo et al., 2000; Esteban et al., 2009; Peters et al., 2014; 


\section{Typical clinical features}

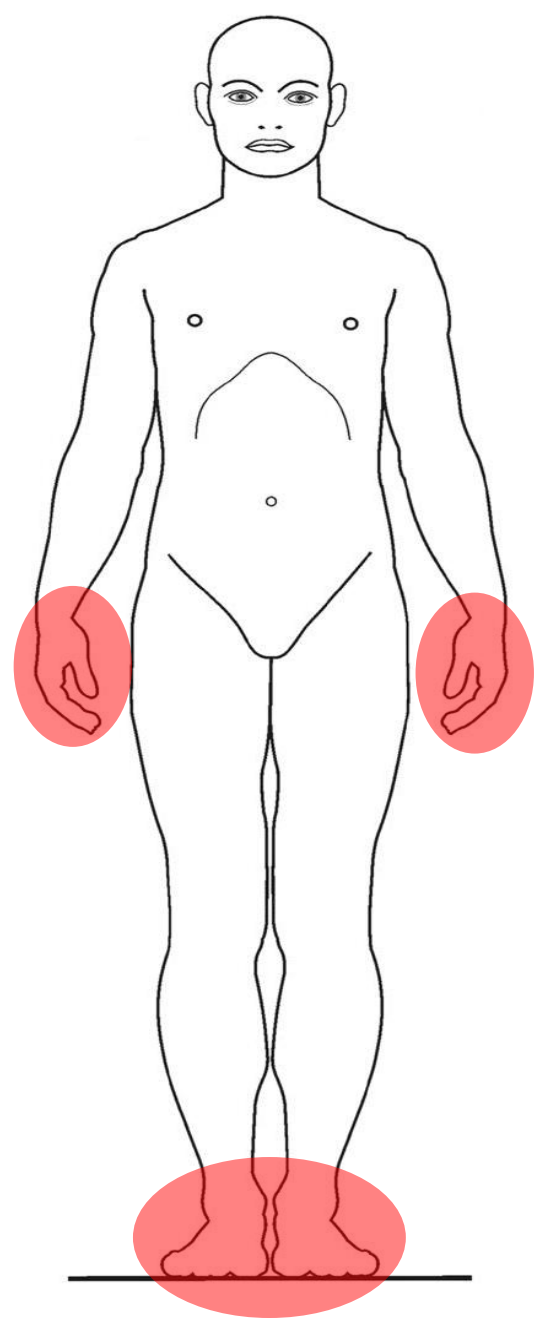

SIGNS

Reduced:

Pin-prick sensitivity

Vibration sense

Reflexes

Temperature sense

\section{SYMPTOMS}

Pain

Numbness

Paraesthesias 


\section{Pathogenesis}




\section{Pathogenesis of HIV-SN}

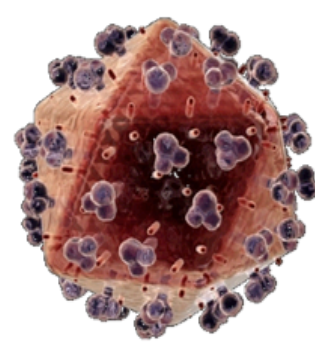

HIV
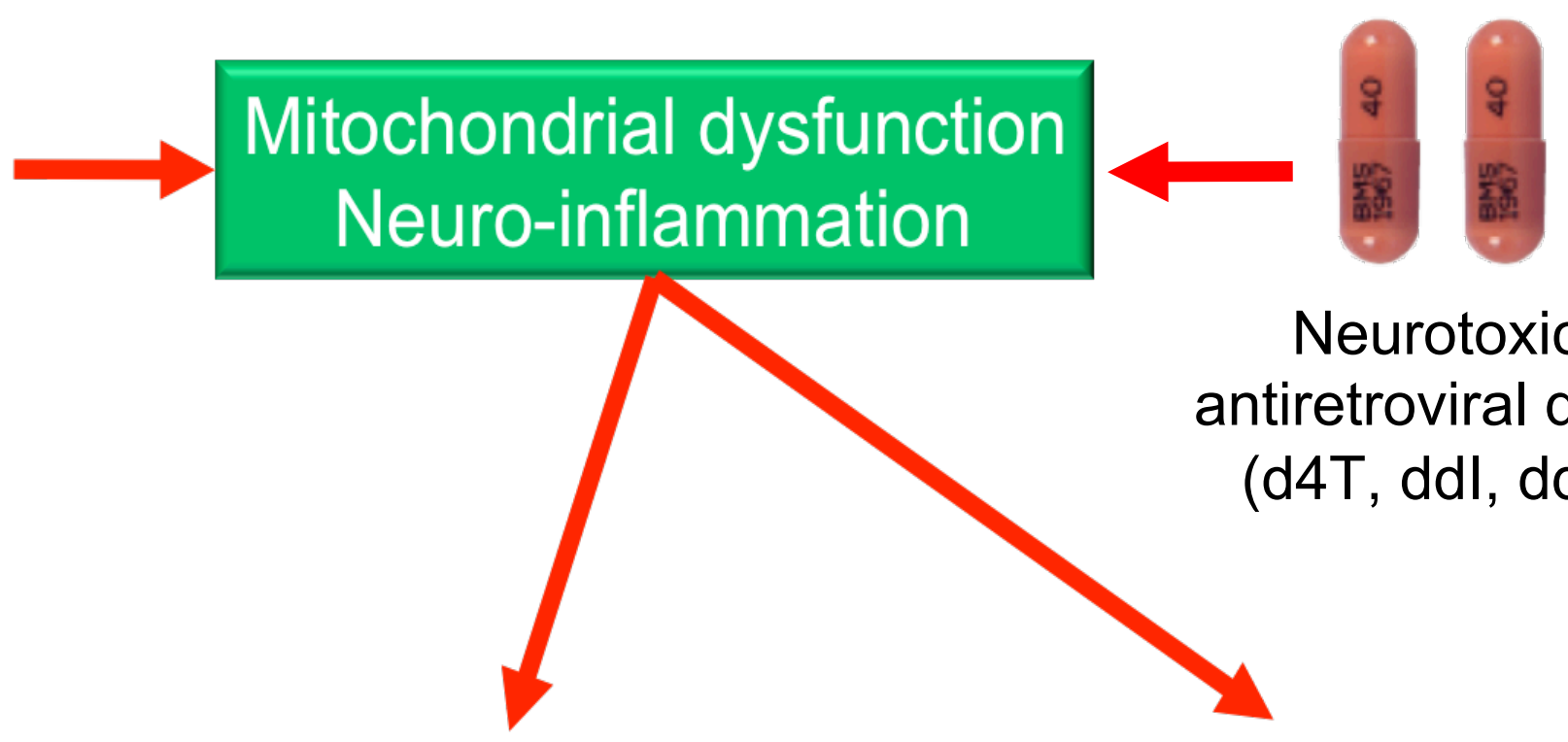

Neurotoxic antiretroviral drugs (d4T, ddl, ddC)

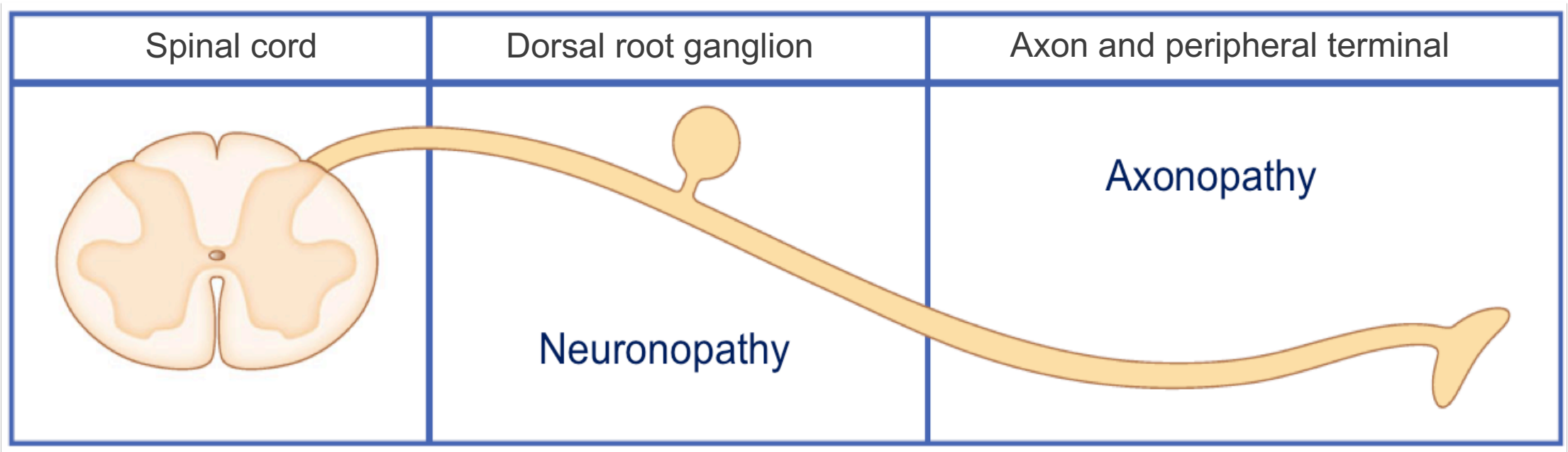




\section{Macrophage infiltration from the skin to the DRG}

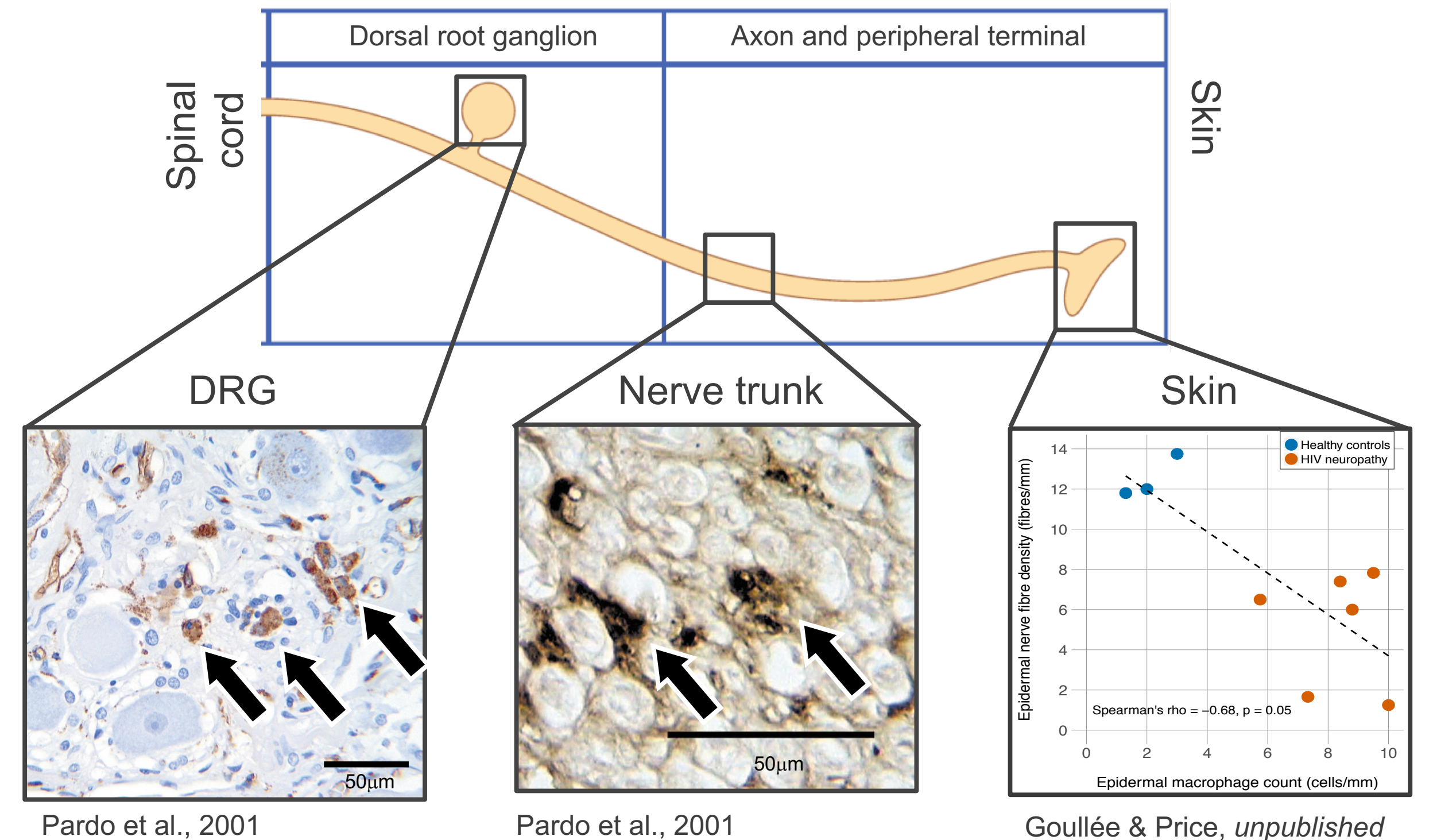

UNIVERSITY OF THE WITWATERSRAND 


\section{Typical clinical features}

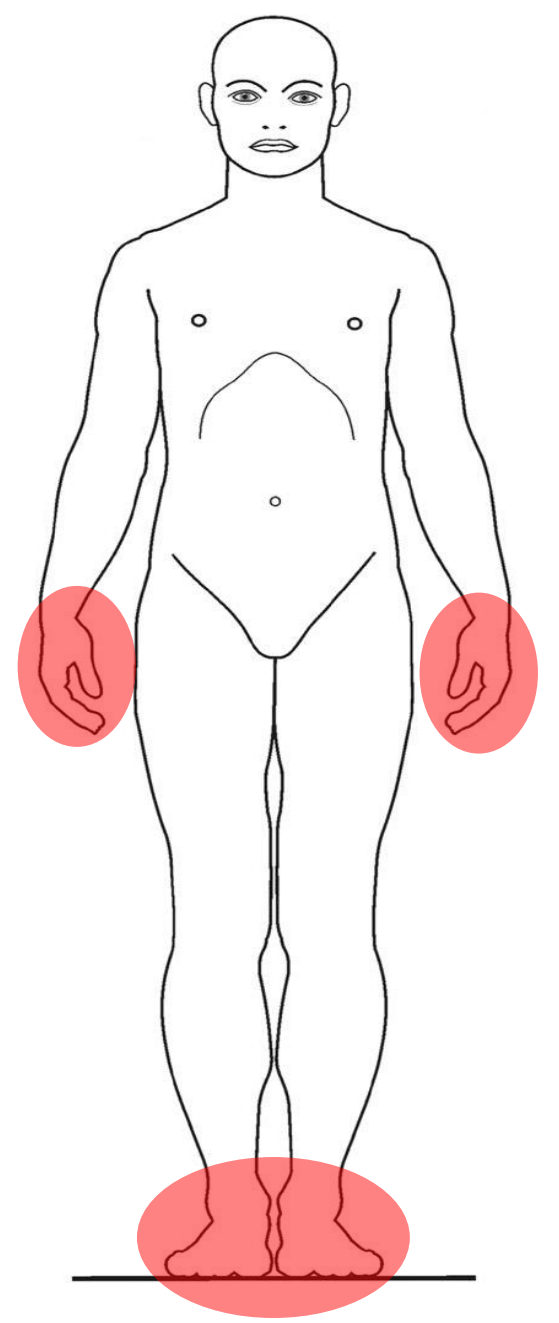

SIGNS

Reduced:

Pin-prick sensitivity

Vibration sense

Reflexes

Temperature sense

\section{SYMPTOMS}

Pain

Numbness

Paraesthesias 


\section{Pain is a common symptom of HIV-SN}

Prevalence ranges of neuropathic pain reported for various causes of nervous system injury

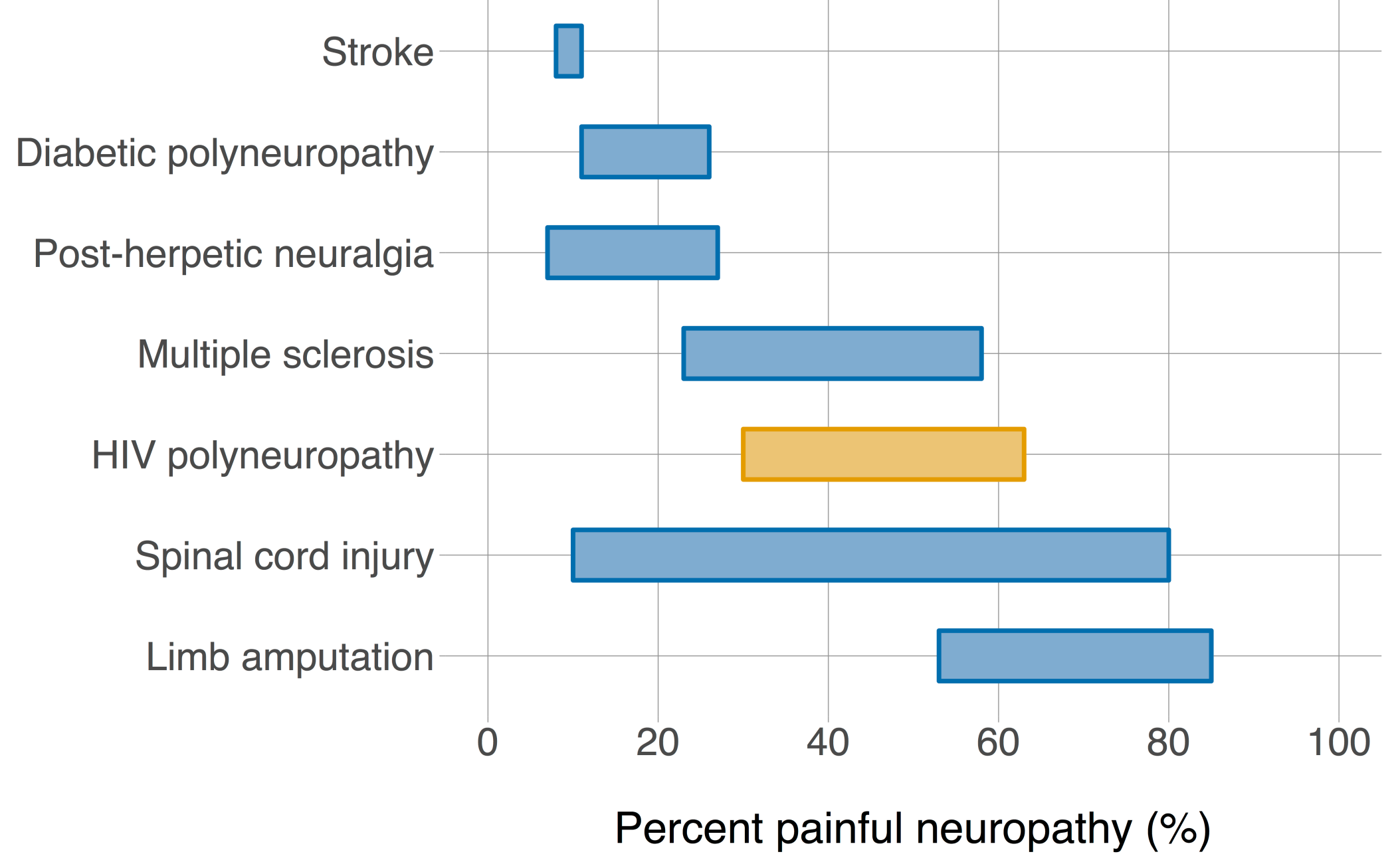




\section{HIV-SN is a major cause of chronic pain}

\section{- Participants:}

324 HIV-positive out-patients with a diagnosis of chronic pain.

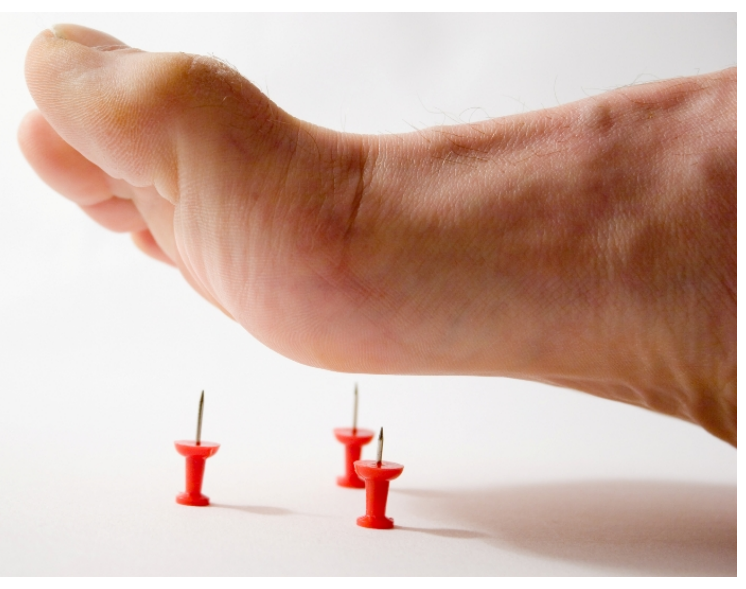

Primary source of pain

Painful peripheral neuropathy

$45-48 \%$

Low back pain

$22-28 \%$

Arthralgia

$6-13 \%$ 


\section{The impact of painful HIV-SN}

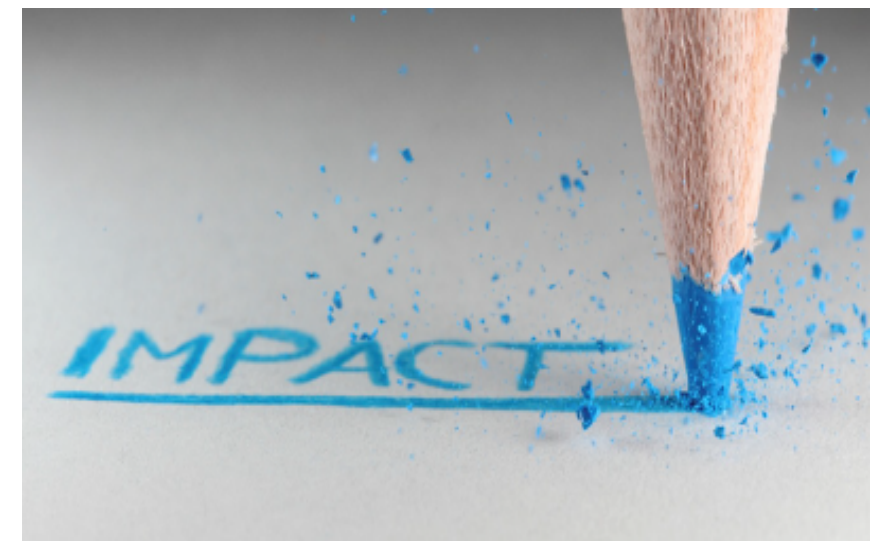

\section{Having pain is associated with}

being unemployed

$\uparrow$ depression and anxiety

$\uparrow$ severity of depressive symptoms

$\uparrow$ sleep disturbance

$\downarrow$ independence

$\downarrow$ social functioning 


\section{Painful HIV-SN in children}

- Participants:

- 135 HIV-infected children

- $\quad 50 \%$ female

- Age: 7 (3 - 11) years

- CD4: 1184 (927-1440) cells/ml

- All exposed to stavudine (d4T)

- SN diagnostic criteria:

Bilaterally reduced / absent ankle reflexes $\underline{O R}$ vibration sense
Low rates of symptomatic HIV-SN in children

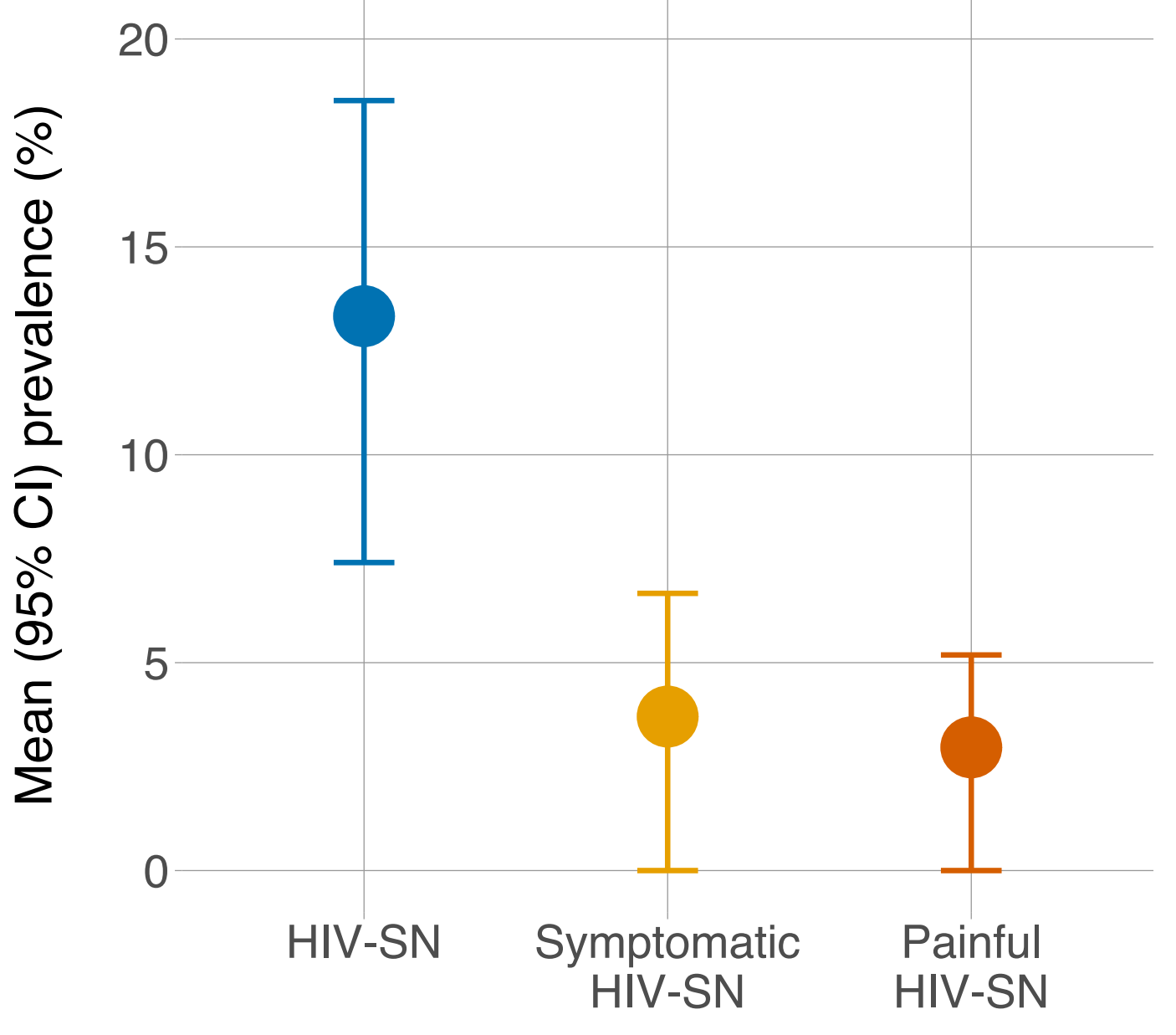




\section{Symptoms are typically moderate to severe}

- Participants:

21 patients with painful HIV-SN

- Assessment: Neuropathic Pain Symptom Inventory (NPSI)
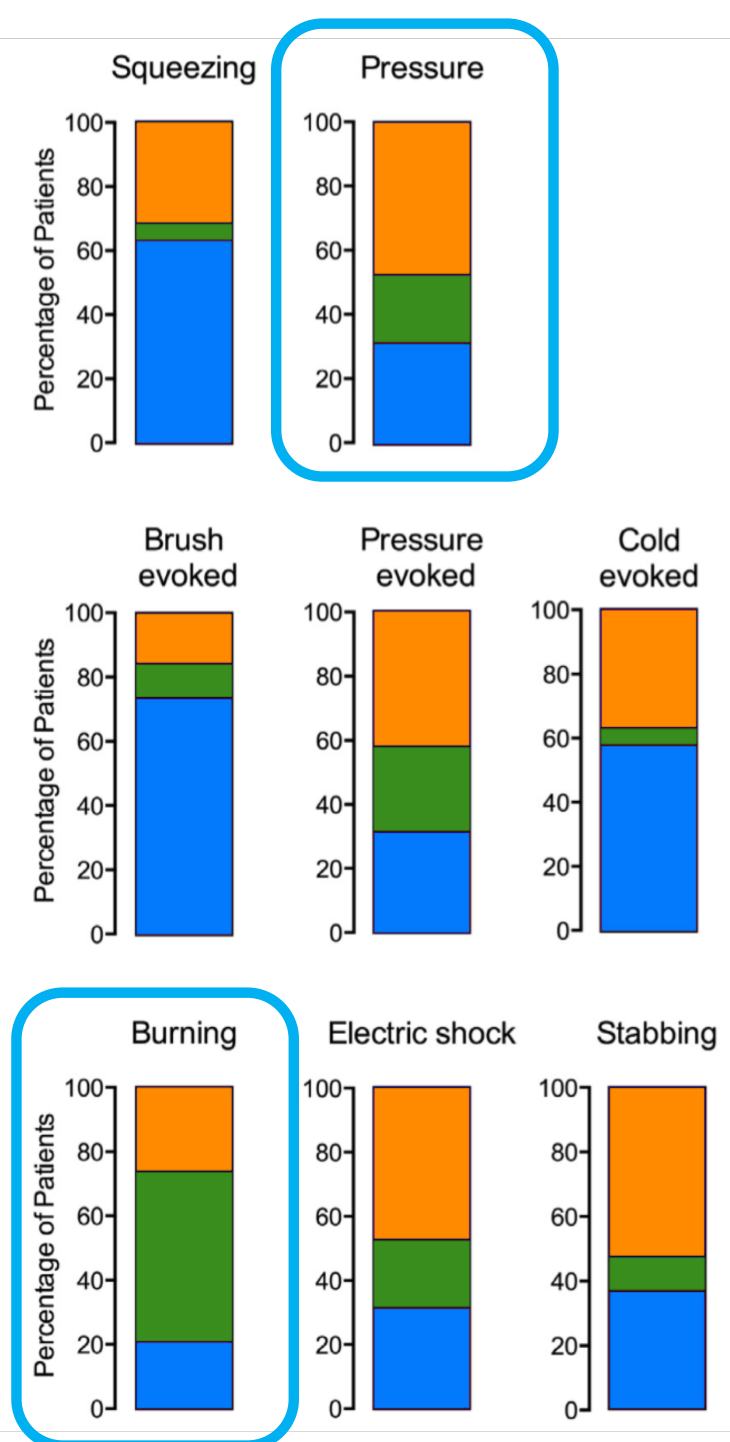

Intensity rating

Severe (7-10)

Moderate (4-6)

Mild (0-3)

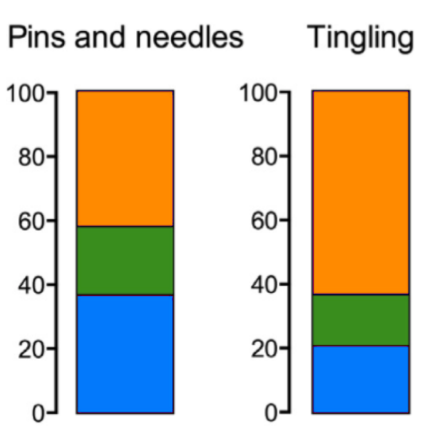




\section{Risk of painful HIV-SN}




\section{Risks for developing painful HIV-SN}

\section{PAIN}

Predictors of new-onset distal neuropathic pain in HIV-infected individuals in the era of combination antiretroviral therapy

Jemily Malvar ${ }^{\mathrm{a}}$, Florin Vaida ${ }^{\mathrm{b}}$, Chelsea Fitzsimons Sanders ${ }^{\mathrm{b}}$, J. Hampton Atkinson ${ }^{\mathrm{b}}$, William Bohannon ${ }^{\mathrm{b}}$, John Keltner ${ }^{b}$, Jessica Robinson-Papp ${ }^{c}$, David M. Simpson ${ }^{c}$, Christina M. Marra ${ }^{d}$, David B. Clifford ${ }^{e}$, Benjamin Gelman ${ }^{\dagger}$, Juanjuan Fan ${ }^{\mathrm{h}}$, Igor Grant ${ }^{\mathrm{b}}$, Ronald J. Ellis ${ }^{\mathrm{b}, *}$, for the CHARTER Group

PAIN 156: 731-739, 2015. DOI: 10.1097/01.j.pain.0000461252.75089.bf

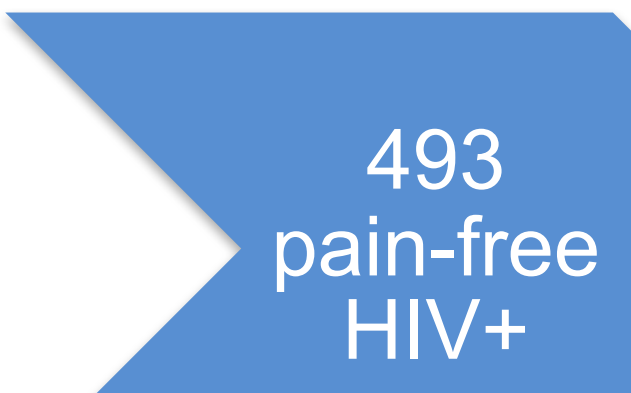

\section{Median follow-up: 24 months (IQR: 12-42; 1961 visits)}

Assessment at each visit

- Pain: Yes / No

- Signs: Bilaterally reduced / absent pin-prick $\underline{\mathrm{OR}}$ vibration sense $\underline{\mathrm{OR}}$ ankle reflexes. 


\section{Incidence of painful HIV-SN}

(incidence: 6.4 cases per 100 person years)

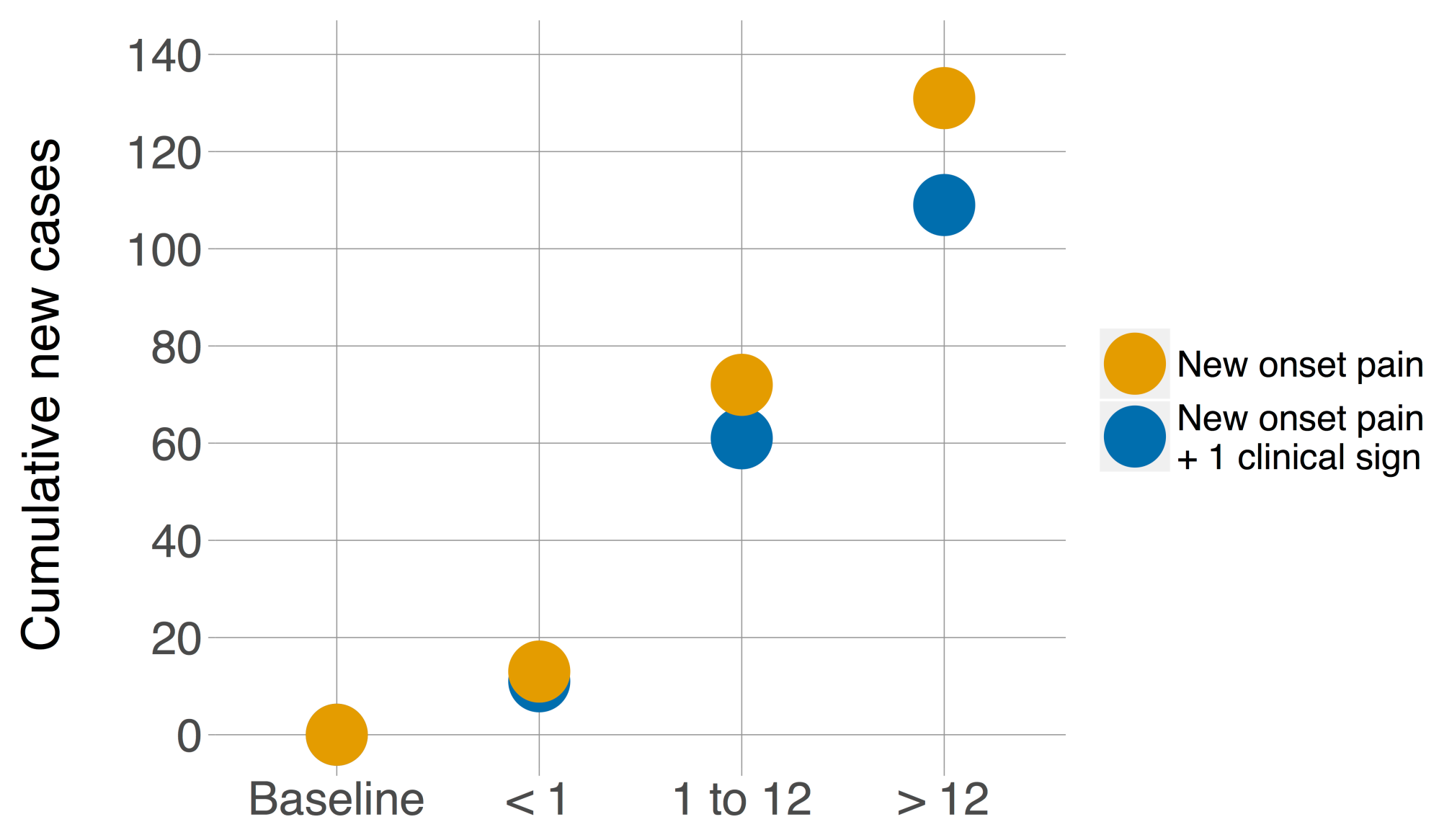

Months 


\section{Risks for developing painful HIV-SN}

Risk factor model (GLMM) for new onset pain and at least 1 clinical sign

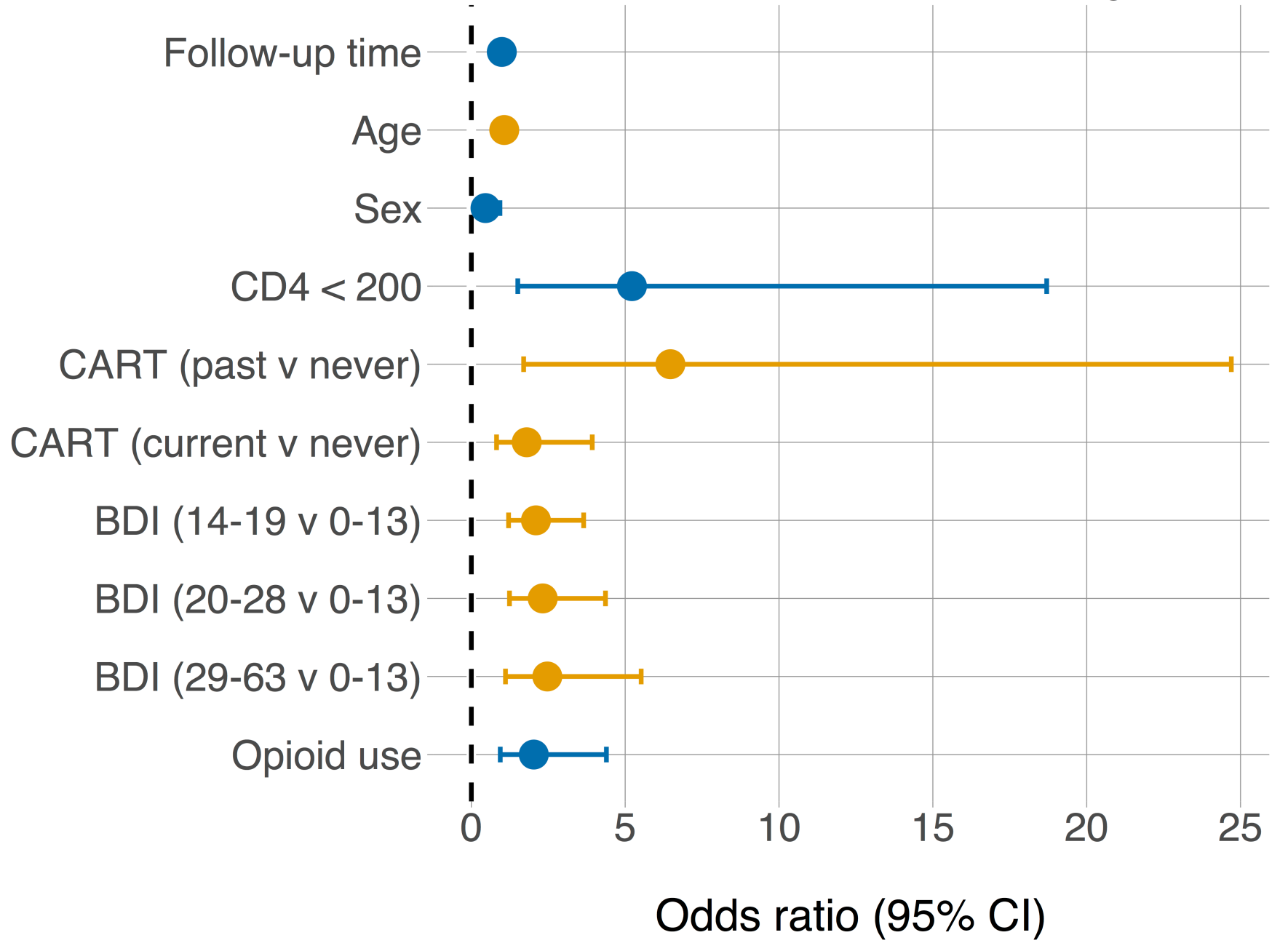




\section{Risks for having painful HIV-SN}

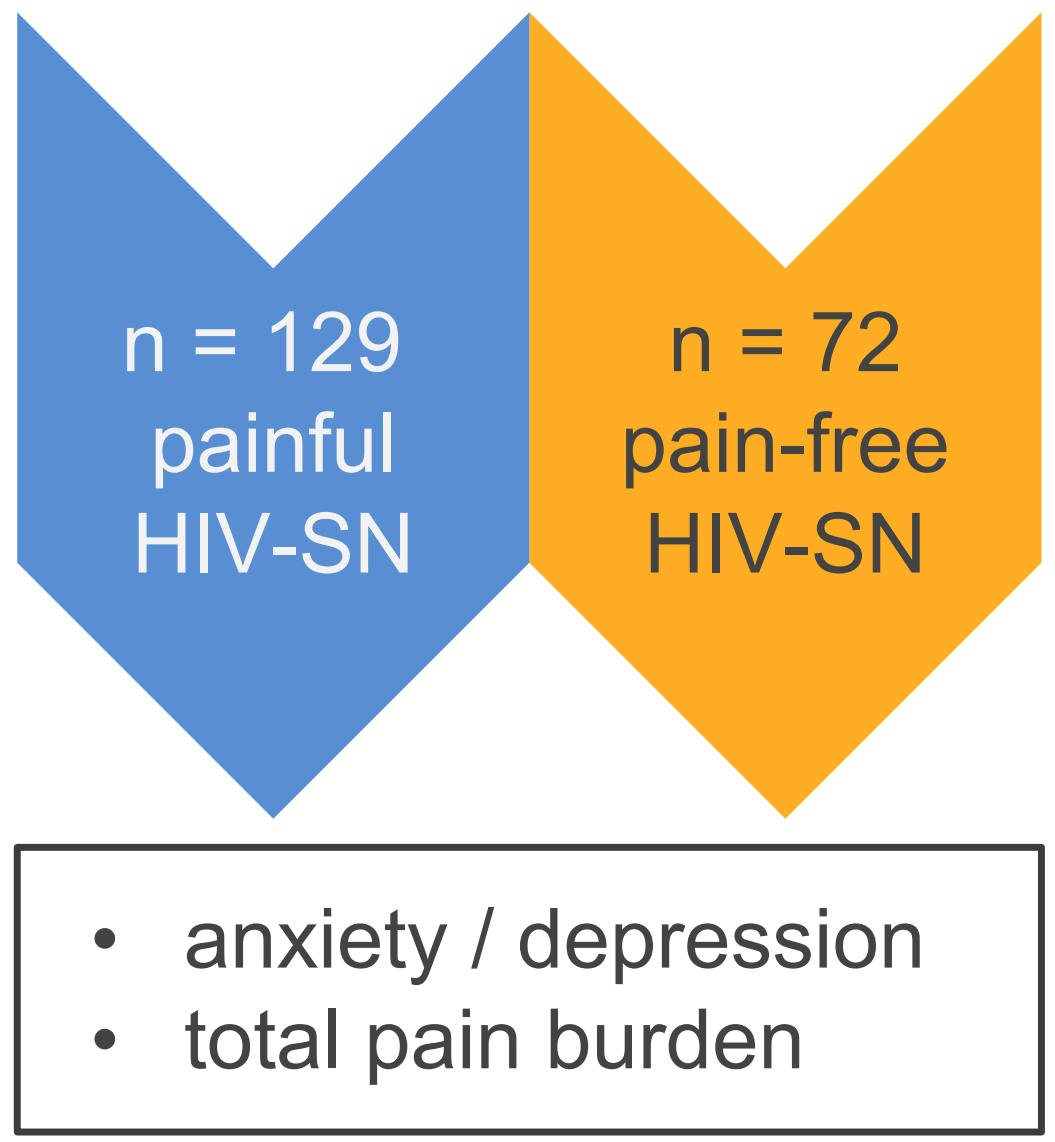

\section{Assessment:}

- Pain: Yes / No

- Signs:

Bilaterally reduced / absent pin-prick sensation $\underline{\mathrm{OR}}$ vibration sense $\underline{\mathrm{OR}}$ ankle reflexes. 


\section{Risks for having painful HIV-SN}

Depression and anxiety

Painful HIV-SN $(n=129)$
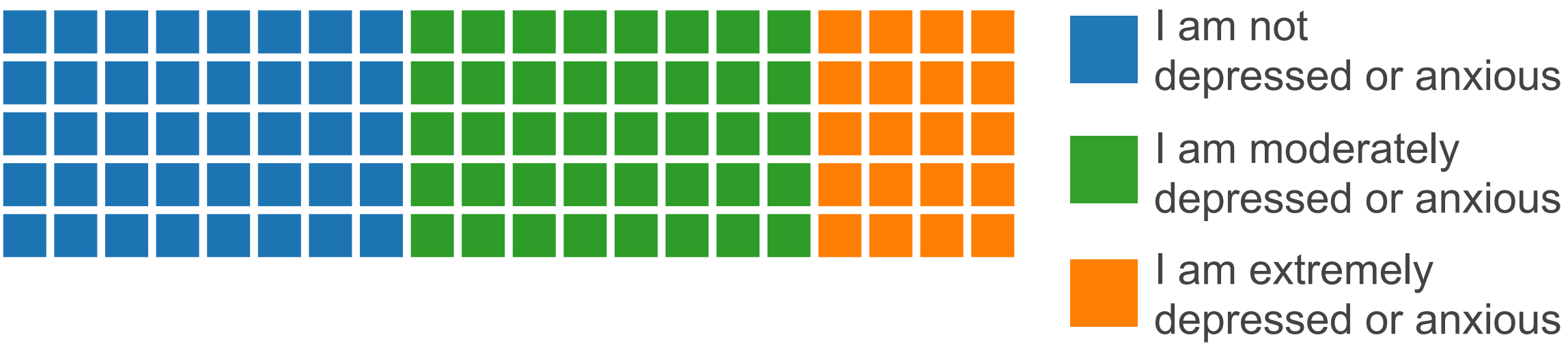

Non-painful HIV-SN ( $\mathrm{n}=72)$

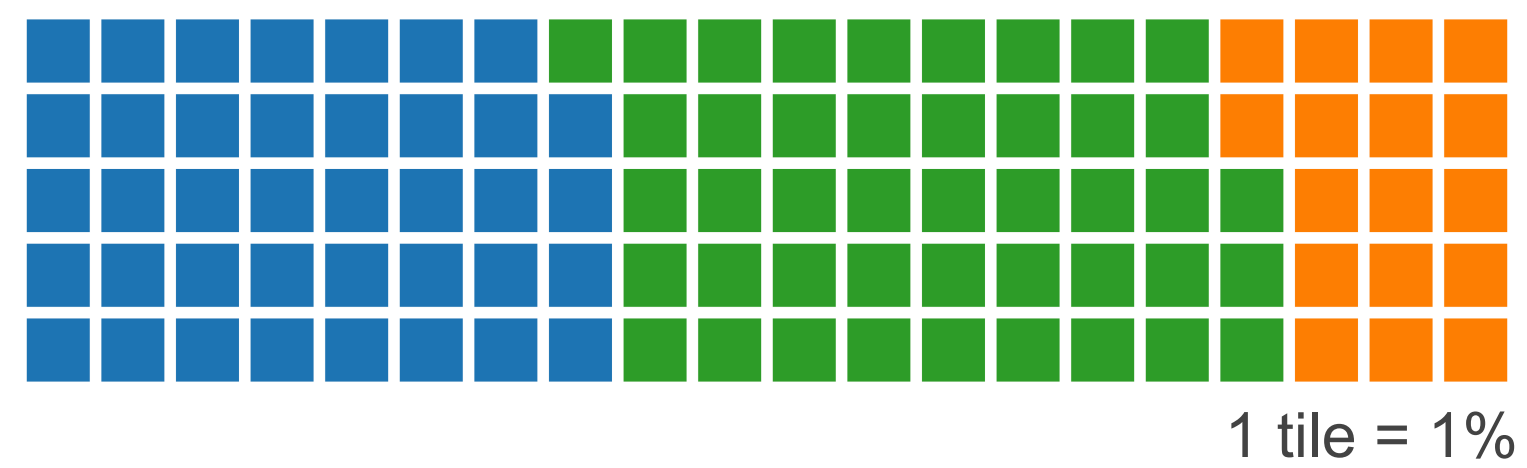




\section{Risks for having painful HIV-SN}

Percent with other pain sites

Painful HIV-SN ( $n=129)$

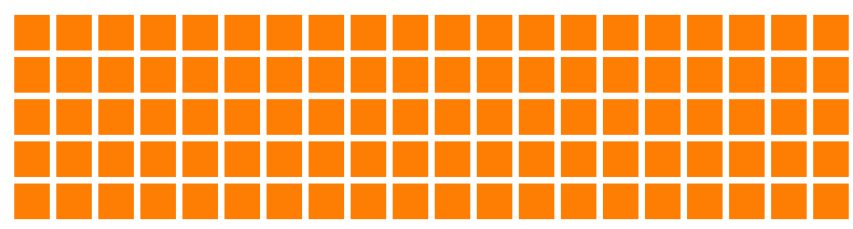

Non-painful HIV-SN ( $n=72)$

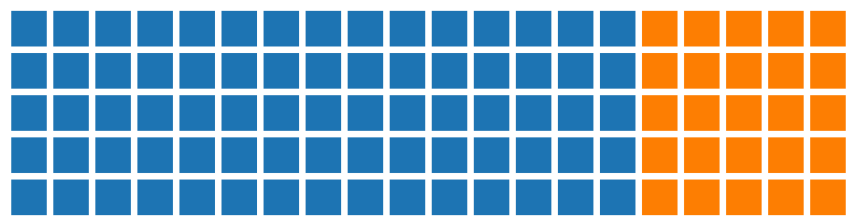

1 tile $=1 \%$

No

Yes
Pain intensity at other sites

Painful HIV-SN ( $n=129)$

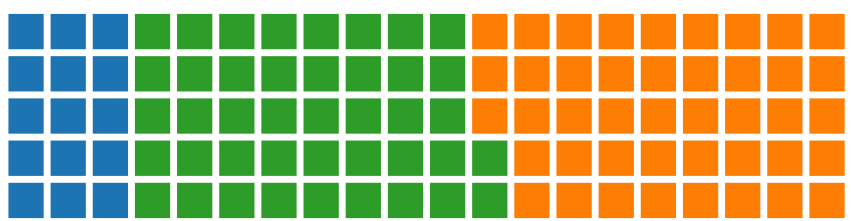

Non-painful HIV-SN (n=18)

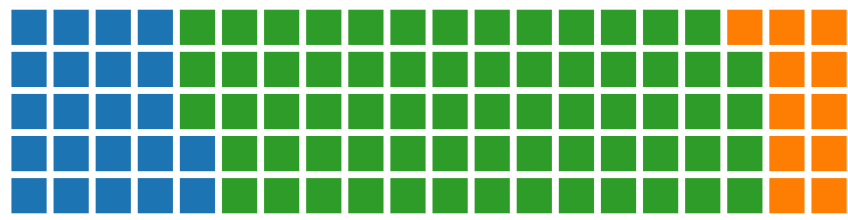

1 tile $=1 \%$

Mild pain

Moderate pain

Severe pain 


\section{Cause or effect: reduced cortical volume?}

- Participants: 241 patients HIV-SN from 5 study centres in the USA (CHARTER)

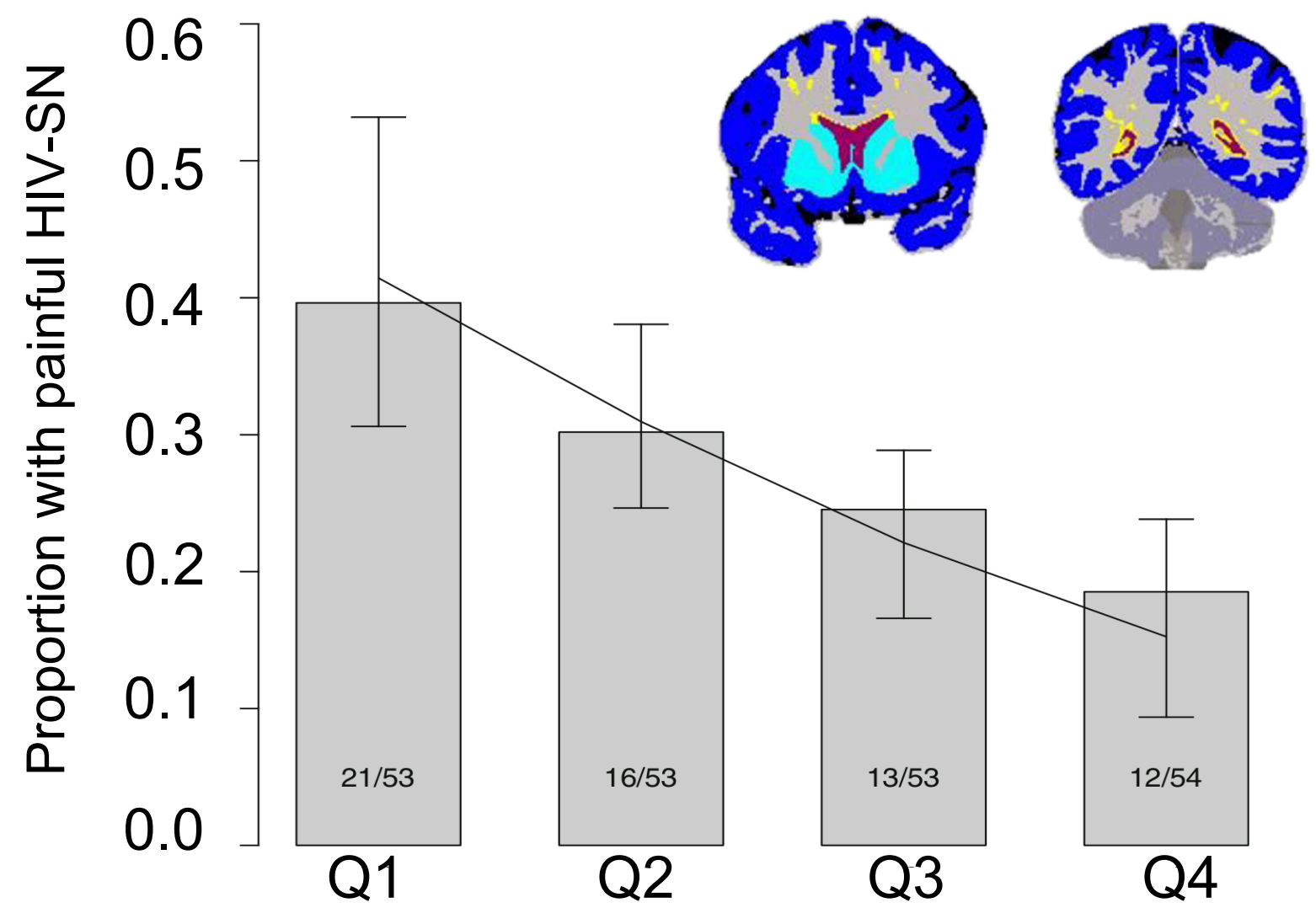

Quartiles of adjusted log cortical volume loss 


\section{Pharmacological management}




\title{
Treatment: there is a lack of evidence
}

Pharmacotherapy for neuropathic pain in adults: a systematic review and meta-analysis

\author{
Nanna B Finnerup*, Nadine Attal*, Simon Haroutounian, Ewan McNicol, RalfBaron, Robert H Dworkin, lan Gilron, Maija Haanpää, Per Hansson, \\ Troels S Jensen, Peter R Kamerman, Karen Lund, Andrew Moore, Srinivasa N Raja, Andrew S C Rice, Michael Rowbotham, Emily Sena, Philip Siddall, \\ Blair H Smith, Mark Wallace \\ Lancet Neurol 2015; 162-73
}

"Pain due to HIV-related painful polyneuropathy...seems more refractory [to treatment] than other types of pain in our meta-analysis."

"This difference might be due to large placebo responses in HIV-related neuropathy trials" 


\section{Large placebo response}

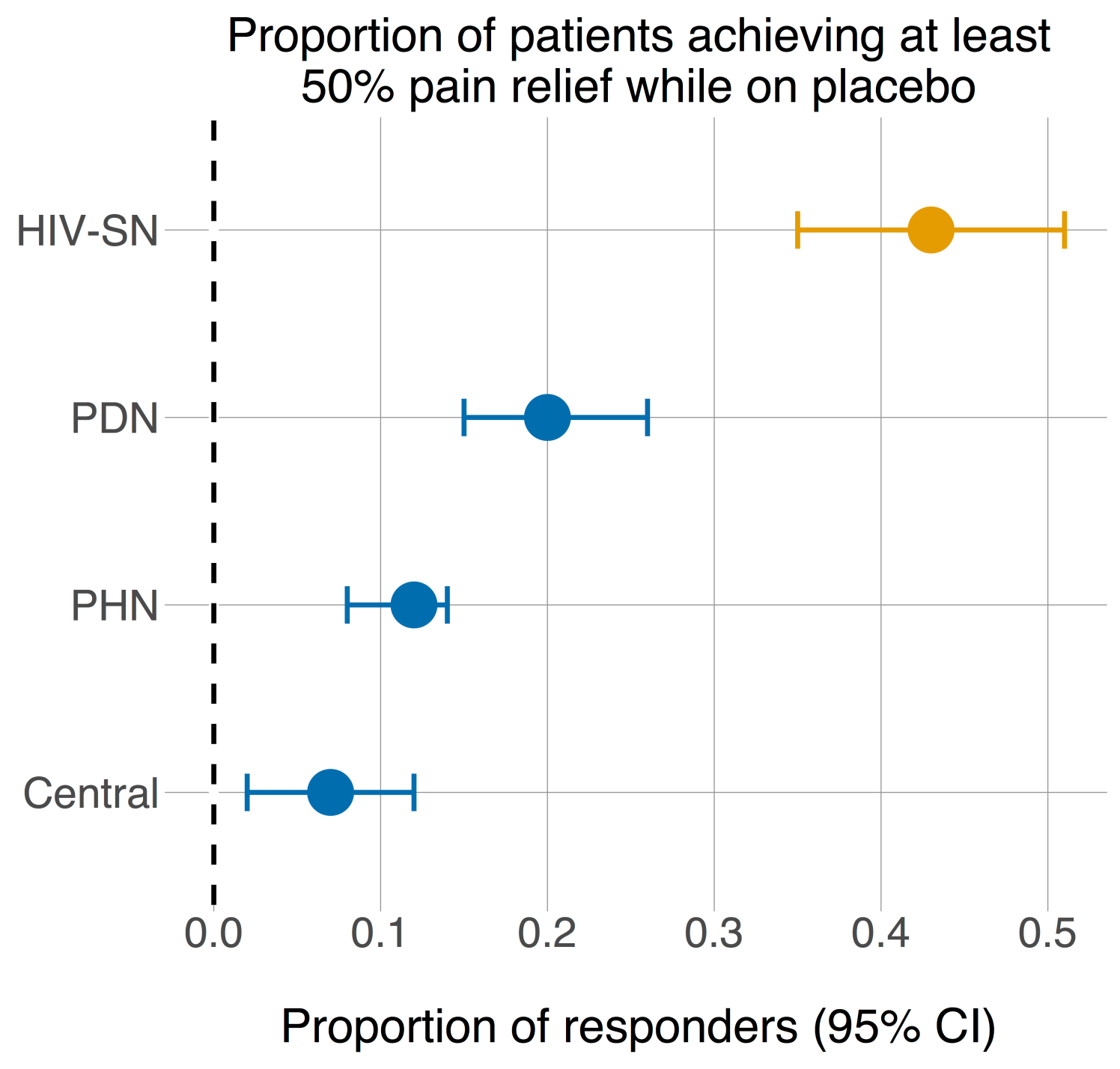


Large placebo response?

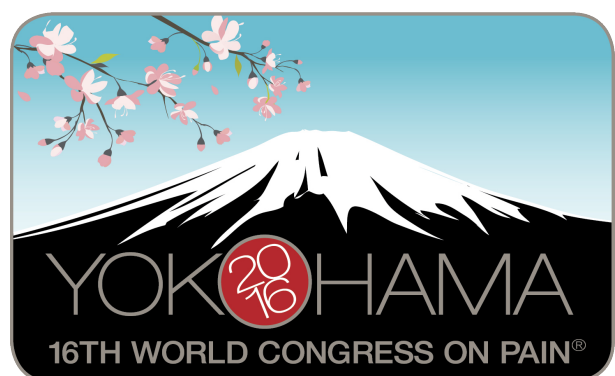

PT0213 A Systematic Review of Factors Influencing Placebo Response in Clinical Trials of Neuropathic Pain: A Comparison of HIV Associated Sensory Neuropathy and Diabetic Polyneuropathy H.Kemp', L. Vase ${ }^{2}$, S. Nguyen ${ }^{3}, A$. Ben Abdallah ${ }^{4}$, A. Rice', N. Finnerup ${ }^{2}$, S. Haroutounian ${ }^{4}$ 


\section{What is being used to manage the pain?}

- Participants: 130 adults with painful HIV-SN
- SN diagnostic criteria:

Bilaterally reduced / absent ankle reflexes $\underline{O R}$ vibration

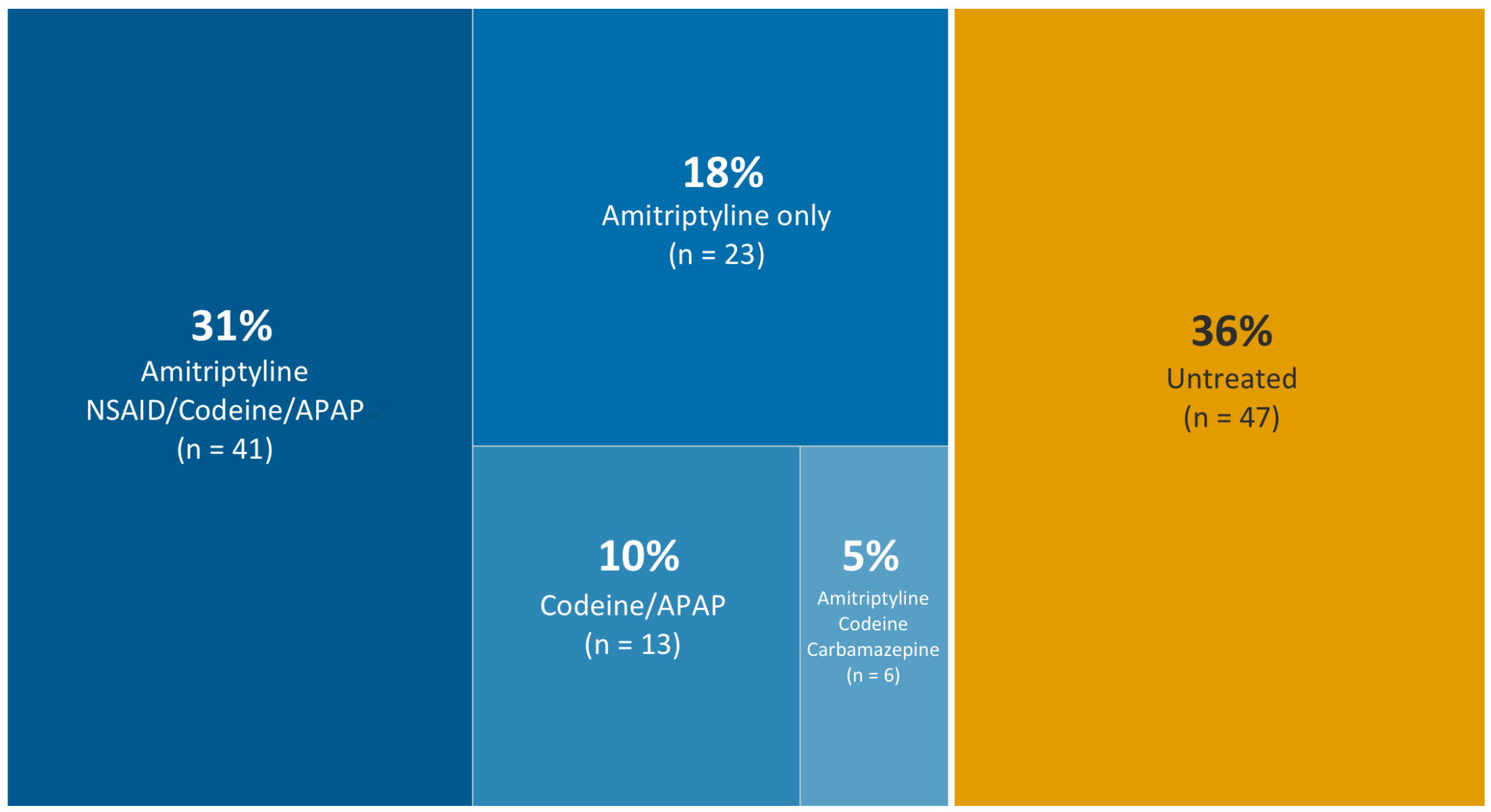

* Median (IQR) amitriptyline dose: 25 (25-75) mg/day | APAP: Paracetamol 


\section{Summary}




\section{Acknowledgments}

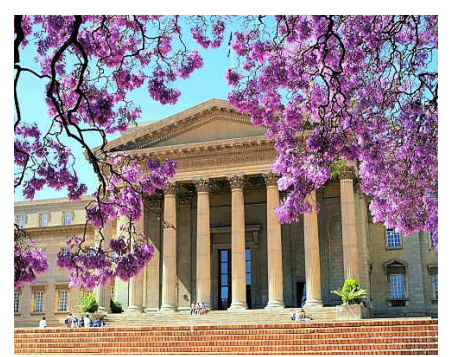

University of the Witwatersrand Antonia Wadley

Zané Lombard

Prinisha Pillay

Liesl Hendry

Asma Shaikh

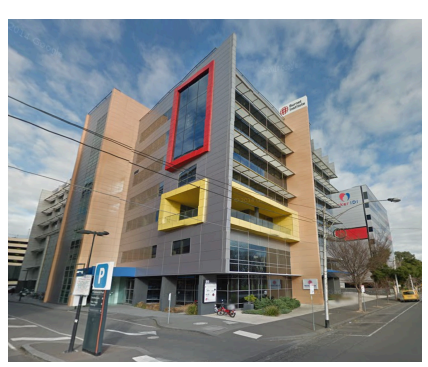

Burnet Institute, Melbourne Kate Cherry
Funding

- National Research Foundation, South Africa

- South African Medical Research Council

- International Association for the Study of Pain

- University of the Witwatersrand

... and

- The Honey Badger

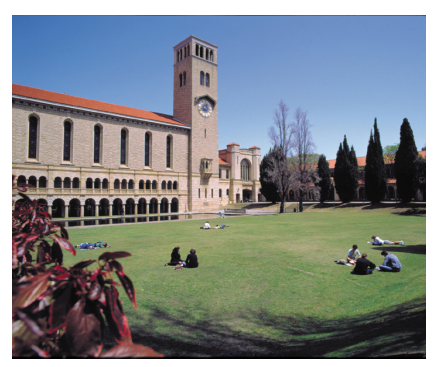

University of Western Australia

Patricia Price

Hayley Goullée

Constance Chew 